\title{
ANÁLISE ECONÔMICA DO CRIME: ABORDAGEM ACERCA DA APLICAÇÃO DO PRINCÍPIO DA EFICIÊNCIA ECONÔMICO SOCIAL EM MATÉRIA PENAL
}

\author{
ECONOMIC CRIME ANALYSIS APPROACH ON THE APPLICATION OF THE \\ PRINCIPLE OF SOCIAL AND ECONOMIC EFFICIENCY IN CRIMINAL MATTERS
}

\author{
Jéssica Gonçalves ${ }^{1}$ \\ Luiz Eduardo Dias Cardoso ${ }^{2}$
}

\begin{abstract}
RESUMO
O artigo discute se a matéria criminal pode ser entendida a partir da Análise Econômica do Direito e seu elemento denominado Princípio da Eficiência Econômico Social. A partir da interdisciplinaridade entre Direito e Economia, que pressupõe a alocação eficiente dos recursos escassos, o artigo, mediante a utilização do método dedutivo e da técnica de pesquisa bibliográfica, investiga se o uso do Princípio da Eficiência Econômico Social, sob o viés do Mínimo Ético Legal, constitui matriz teórica explicativa do crime, para além da visão punitiva e persecutória, inserindo-se critérios como: crime econômico, reflexo social e o custo externo à sociedade.
\end{abstract}

Palavras-chave: Análise Econômica. Princípio da Eficiência Econômico Social. Direito Penal.

\begin{abstract}
The article discusses the criminal matter can be understood from the Economic Analysis of Law and his element called Principle of Social and Economic Efficiency. From the interdisciplinarity between law and economics that assumes the efficient allocation of scarce resources, the article, using the deductive method and the literature technique, investigates the use of the Principle of Social and Economic Efficiency, under the bias of the Ethical legal minimum are explanatory theoretical frameworks of the crime, in addition to punitive and persecutory vision, inserting criteria such as economic crime, social reflection and the external cost to society.
\end{abstract}

Keywords: Economic Analysis. Principle of Social and Economic Efficiency. Criminal Law.

\footnotetext{
${ }^{1}$ Doutoranda e Mestre em Direito pela UFSC. Pós-Graduada em Direito Aplicado e em Direito Público pela FURB e em Direito Processual Civil pela UFSC. Graduada em Direito pela Unisul. Santa Catarina (Brasil).

${ }^{2}$ Mestrando e Bacharel em Direito pela UFSC. Pós-graduando em Direito Penal e Processo Penal pela Univali. Assessor Jurídico no TJSC. Santa Catarina (Brasil). E-mail: luizeduardo.cardoso@gmail.com.
} 


\section{INTRODUÇÃO}

As relações humanas ocorrem em meio às transações econômicas, políticas e sociais, de modo que o Direito, enquanto balizador do comportamento humano, recebe estigmas de fontes externas. Não significa isto dizer que o ordenamento jurídico sofra a colonização, na sua normatividade, de sistemas alheios, porém não se encontra solitário na dinamicidade social.

Tendo em vista que o desenvolvimento humano ocorre em meio à dinâmica mercadológica, e que o Direito objetiva regulamentar tais comportamentos, a dicotomia entre a Ciência Econômica e a Ciência Jurídica pode mostrar-se destrutiva, porquanto a eliminação da interdisciplinaridade impede o exame dos problemas jurídicos para além da realidade abstrata da norma.

Partindo desse pressuposto, muito embora as interações entre as duas Ciências pareçam diálogos entre estranhos - especialmente porque a metodologia aplicada pelo Sistema Jurídico importa em ser hermenêutica com aspiração na justiça, ao passo que a Econômica, implica na matemática com bases empíricas -, a questão é que o estudo interdisciplinar se revela importante para a compreensão do sistema jurídico como um todo, notadamente pelo enfoque criminal que se pretende com o presente artigo.

Desta forma, se a busca pela ordem social adequada perpassa por diversos ângulos, não se mostrando apropriado esgotar os estudos na eleição de um único método, o presente artigo sugere o seguinte problema: pode o instrumental da Análise Econômica do Direito (AED), em especial, o elemento microeconômico do Princípio da Eficiência Econômico Social - PEES, ser utilizado para interpretação e aplicação de matérias de ordem pública, como o direito penal e sua tipologia criminosa?

Para a resposta a este problema, o artigo utiliza-se do método dedutivo e da técnica de pesquisa bibliográfica. Especificamente, recorta-se o tema em tópicos consistentes na relação entre Direito e Economia, expansão da Análise Econômica do Direito e o Princípio da Eficiência Econômico Social - PEES, para, a partir desta teoria de base, deduzir e generalizar a possibilidade de aplicar os conceitos deste Princípio na seara criminal.

O objetivo, portanto, é investigar se o uso do Princípio da Eficiência Econômico Social, sob o viés do Mínimo Ético Legal, constitui matriz teórica que proporciona a aplicação da Análise Econômica do Direito à fenomenologia criminal, bem como a adaptação daquela teoria à realidade fática e normativa brasileira. 


\section{DA RELAÇÃO ENTRE O DIREITO E A ECONOMIA}

$\mathrm{O}$ atual contexto neoliberal globalizado, tipicamente capitalista ${ }^{3}$, demarca mudanças na relação entre Estado, mercado e a função do Poder Público, dentre as quais, o ente Estatal abandona sua posição de passividade para tornar-se protagonista do setor econômico, sob o parâmetro da eficiência. E, nessa circunstância, os fenômenos jurídicos, além de encontrarem-se inseridos na órbita política e social, adentram na esfera econômica, representando o Direito um paradoxo: sua origem advém dos fatos econômicos e tais fatos também criam o ordenamento jurídico de modo eficiente.

Disso decorre que a Ciência Econômica, responsável pelo estudo da relação entre a escassez dos recursos versus as necessidades humanas ilimitadas, entrelaça-se com a Ciência Jurídica, cujo escopo é o enquadramento das mencionadas relações nas normas jurídicas. Não houvesse escassez ou a necessidade de repartir os bens entre os homens, não existiriam sistemas econômicos, tampouco a própria Economia - que é, fundamentalmente, o estudo da escassez e dos problemas dela decorrentes para satisfazer a necessidade humana.

A exata compreensão do objeto da Ciência Econômica evoluiu historicamente e, contemporaneamente, o objeto cuida da formação da riqueza e dedica-se às questões ligadas à repartição. Segundo José Paschoal Rossetti (1990, p. 71), o "tratamento do binômio desenvolvimento - repartição - em nível de estudo da Economia atual, mantém-se ligado à dicotomia escassez recursos x necessidades ilimitadas", ou seja, desenvolvimento vinculado ao aproveitamento ótimo dos recursos disponíveis e à repartição intrínseca às necessidades ilimitadas. Desse objeto resulta a divisão no estudo da Ciência Econômica em dois principais ramos:

a) Macroeconomia: "cuida do desempenho das economias nacionais e das políticas que os governos usam para tentar melhorar o desenvolvimento", concentrando-se no estudo "[...] agregativo da atividade econômica, magnitudes globais, com vistas à determinação das condições gerais de crescimento" (ROSSETTI, 1990, p. 71);

\footnotetext{
${ }^{3}$ Corrente do pensamento político-econômico, surgida no pós-guerra, na Europa e na América do Norte, em que predominava o capitalismo como sistema de organização social, com o objetivo de combater o Estado de bem-estar e, tendo como preceitos básicos: a liberdade econômica, o individualismo e a contenção da intervenção estatal. Para maiores informações, vide: ANDERSON, Perry. Balanço do neoliberalismo. In: SADER, Emir; GENTILLI, Pablo. (Orgs.). Pós-neoliberalismo: as políticas sociais e o Estado democrático. 6. ed. Rio de Janeiro: Paz e Terra, 2003. p. 9.
} 
b) Microeconomia ou teoria dos preços: examina as escolhas individuais e o comportamento de grupo em mercados individuais sob condições de escassez e suas implicações para o comportamento de preços, ou seja, preocupa-se com o comportamento dos consumidores e produtores, com vistas à compreensão do funcionamento geral do sistema econômico e, "por isso, também é conhecida como teoria dos preços uma vez que é através do sistema de preços que as ações dos produtores e consumidores podem ser articuladas" (ROSSETTI, 1990, p. 51$52)$.

Assim, a área Macroeconômica é responsável pelo estudo dos agregados econômicos, tais como: produto nacional, renda, poupança, despesas e investimentos. Já a microeconomia serve para compreender o comportamento racional e individualista dos homens e as suas tomadas de decisões frente à escassez dos recursos. Tendo em vista que a abordagem Microeconômica trabalha a teoria do comportamento humano na análise do custo-benefício na tomada das decisões, para o presente artigo, apenas este ramo é considerado, já que se pretende discutir acerca do Princípio da Eficiência Econômico Social no âmbito criminal.

A partir desta conceituação, denota-se o quão distante a Ciência Econômica mostra-se, em princípio - e apenas em princípio -, do Direito, pois ambos apresentam metodologias distintas, na medida em que o primeiro aspira à cientificidade pela matemática, ao passo que o segundo busca a Justiça de modo hermenêutico.

Definido dessa forma, ainda que a abordagem seja distinta, tantos os economistas, quanto os juristas, entrelaçam-se num diálogo interdisciplinar, pois estão preocupados em encontrar a solução para que o ser ("o mundo dos fatos") se transforme no "dever-ser"; ou seja, modernamente, ambos procuram compreender o comportamento humano, prevê-lo e regulamentá-lo. Além disso, ambas as Ciências não se limitam à discussão do papel da Eficiência ${ }^{4}$ na determinação das normas jurídicas, em que pese neste artigo, o enfoque será feito pelo exame da (im) possibilidade da aplicação do Princípio da Eficiência Econômico Social no âmbito da norma jurídica penal.

Por isso, em um primeiro momento, a dogmática jurídica passa a restringir o uso da Ciência Econômica ao estudo das leis antitrustes, regulamentos e indenizações monetárias, limitando o aprofundamento na matéria do Direito Econômico. A Ordem Econômica serve, então, para responder perguntas vinculadas às instituições e contratos. Porém, mais tarde,

\footnotetext{
${ }^{4}$ Segundo Bruno Salama Meyerhof Salama, a referência da colonização do sistema Econômico sobre o Jurídico, pela óptica da Eficiência, exclui a análise descritiva da realidade jurídica enquanto formulação do "dever ser". (SALAMA, 2008).
} 
precisamente na década de 1960, muitas dúvidas passam a surgir, momento em que a Ciência Econômica propôs balançar a certeza e a segurança previstas no método hermenêutico do Direito, expandindo a Análise Econômica para outros ramos jurídicos.

Assim, enquanto o Direito é a técnica de regulamentar o comportamento humano, a Economia representa a ciência que estuda esse comportamento e suas consequências no mundo em que os recursos são escassos, de modo que a Análise Econômica do Direito (AED) é o resgate dessa relação, com o objetivo de auxiliar o Legislador ou o Juiz na formulação de escolhas eficientes no que toca à redução dos custos.

\section{O DESENVOLVIMENTO DA TEORIA DENOMINADA ANÁLISE ECONÔMICA DO DIREITO}

O ponto histórico demarcado como de intersecção, considerado como gênese do movimento entre Direito e a Ciência Econômica - que mais tarde é batizado de Análise Econômica do Direito -, remonta ao século XVIII a partir de dois autores: o primeiro, Adam Smith, discorre sobre os efeitos econômicos da legislação mercantilista; o segundo, Jeremy Bentham, de geração posterior à de Adam Smith, faz referência à Análise Econômica das Leis que regulam o comportamento de atividades no interior do mercado, tais como: delitos; acidentes; responsabilidade civil; matrimônio; contaminação e processos jurídicos, entre outras (ROEMER, 1994, p. 6).

Posteriormente, dois marcos contribuem para a evolução do movimento, sendo o primeiro correspondente ao período anterior a 1960, quando a análise do Direito antitruste dominava a conjugação entre as ciências Jurídicas e Econômicas; e o segundo, a partir de 1960, com ampla aplicação da Ciência Econômica ao sistema legal. Entretanto, a consolidação da teoria traduzida pela terminologia da Análise Econômica do Direito não apresenta unicidade de ideias, até porque há todo o percurso histórico, desde o ano de 1960, com a publicação dos artigos de Guido Calabresi e de Ronald Coase, até a sua consagração como disciplina autônoma, a partir dos escritos de Richard Posner (POSNER, 2007, p. 23).

Nesse sentido, Everton das Neves Gonçalves e Joana Stelzer (2012) explicam que, a partir dos estudos de Guido Calabresi e Ronald Coase, tem-se “inovador discurso jurídico voltado ao perfil mais técnico-racional, de tendência reconstrutivista-realista, que o outrora lógico-formal". Especificamente, com Guido Calabresi, consagra-se a aplicação da Economia 
Clássica no exame da norma, na medida em que seu trabalho nunca teve a orientação do laissezfaire que demarca a Escola de Chicago e não deve com essa vertente agrupar-se, salvo quanto à análise que põe em campo a transgressão da lei e a reparação do dano desde o ponto de vista do direito consuetudinário.

Já Ronald Coase, em seu artigo escrito na Universidade de Virgínia, analisando as ideias de Pigou, publicadas em seu "The Economics of Welfare", ensina a partir - e diferentemente - de Pigou, que o Direito e sua normatividade devem observar a reciprocidade de interesses entre os indivíduos. As normas influenciam na distribuição ou redistribuição da riqueza, de modo que os direitos de propriedade e da responsabilidade civil modificam a Economia. O autor chamou a atenção para o que ficou conhecido como Teorema de Coase muito embora não lhe tenha dado o nome -, ao sustentar que, quando os Custos de Transação são iguais a zero, a atribuição do direito de propriedade não afetará a eficiência com que os recursos deverão ser alocados.

Complementando a trilogia de autores, surge o aluno de Coase, e o mais notável nome da AED Contemporânea, o juiz norte-americano Richard Posner, cuja obra "Economic Analysis of Law”, de 1973, proporcionou cientificismo à disciplina e expansão da teoria ao mundo jurídico. Entendendo que o Direito encontrava-se em estágio pré-científico, o Autor passa a interpretar a lógica pragmática baseada nos princípios econômicos como instrumental às decisões jurídicas, as quais devem ser orientadas pela análise do "custo e benefício em prol da maximização da riqueza".

A partir destas intersecções históricas, Pedro Pacheco Mercado (1994, p. 22-23) define a Análise Econômica do Direito (AED) nos seguintes termos:

\begin{abstract}
A AED se define pela aplicação da teoria econômica, mais precisamente, da teoria microeconômica de bem-estar na análise e explicação do sistema jurídico [...]. A AED nos apresenta um novo instrumental, novas técnicas argumentativas e novas categorias que, extraídas dos desenvolvimentos da ciência econômica, apresentam-se neste movimento como pilares para construção de uma ciência jurídica a altura dos tempos. A renovação da Ciência Jurídica através da adoção da perspectiva interdisciplinar, peculiar pelo peso que tem à Ciência Econômica, a utilização de técnicas como a análise do custo e benefício na elaboração das políticas jurídicas, na justificação das decisões judiciais, a abertura decidida do discurso jurídico ao tema das consequências econômico-sociais do Direito, ou a consideração da eficiência econômica como valor jurídico, são, entre outros, sinais evidentes dessa inovação em que a Análise Econômica do Direito apresenta a si mesma. ${ }^{5}$ (tradução nossa).
\end{abstract}

\footnotetext{
${ }^{5}$ Original: “el AED se define por la aplicación de la teoría económica, más precisamente, de la microeconómica del bienestar em el análisis y explicación del sistema jurídico[...] El AED nos aporta um nuevo instrumental, nuevas técnicas argumentativa y nuevas categorias que, extraídas de los desarrollos de la ciência económica, se presentam em este movimento como los pilares para la construcción de uma ciência jurídica a la altura de los tempos. La renovación de la ciencia jurídica como el análisis coste-benefício en la elaboración de las políticas jurídicas y en la
} 
A AED consiste, assim, no emprego da Teoria Econômica no Direito para compreensão da racionalidade dos sujeitos no sistema legal na medida em que aplica suas premissas na elaboração das normas ou no silogismo decisório. Neste âmbito, constitui estudo interdisciplinar entre a Teoria Econômica e o Direito, com o objetivo de auxiliar, seja o Legislador ou o Juiz, a fazer escolhas melhores - isto é, eficientes.

\section{O PRINCÍPIO DA EFICIÊNCIA COMO ELEMENTO DA ANÁLISE ECONÔMICA DO DIREITO}

A Análise Econômica do Direito reformula o Sistema Jurídico como objeto de estudo a partir do ponto de vista Econômico, mormente mediante a reflexão acerca de problemas relativos, por exemplo, à eficiência da norma, custo dos instrumentos jurídicos e as consequências econômicas das intervenções jurídicas. O estudo dessa teoria não significa a defesa de uma única solução, mas a opção de examinar o fenômeno jurídico a partir da visão economicista, assim como se fosse analisado pela abordagem política, histórica, sociológica ou antropológica.

Portanto, a Análise Econômica do Direito (AED) interage de diversas maneiras na organização da vida em sociedade, podendo ser aplicada ao Sistema Jurídico-Normativo Brasileiro, notadamente porque, embora o movimento não apresente união e convergência em razão das diversas Escolas ${ }^{6}$, representa a aplicação do elemento Econômico denominado de Eficiência, no interior do Direito.

Analisar o Direito conforme critérios e métodos econômicos nada mais é do que procurar elaborá-lo, interpretá-lo e aplicá-lo de modo a alcançar a Eficiência Econômica, entendida esta como a maximização na geração e distribuição dos recursos disponíveis. Com efeito, é indispensável que os atores do Direito tomem suas decisões, buscando a melhor alocação dos bens, isto é, que seus posicionamentos sejam eficientes, na medida em que as demandas são maiores do que os recursos.

justificación de las decisiones judiciales, la apertura decidida del discurso jurídico al tema de las consecuencias económico-sociales del derecho, o la consideración de la eficiência económica como valor jurídico son, entre outros, signos evidentes de esa innovación con la que el análisis económico del derecho se presenta a sí mismo".

${ }^{6}$ A teoria apresenta diferentes enfoques: a) Tradicional da Escola de Chicago; b) Neoinstitucional ou Property Rights; c) Escolha Pública ou Public Choice; d) Estudos da Crítica Jurídica. 
Partindo desse pressuposto, no que tange às bases epistemológicas, as perspectivas das diversas Escolas vinculam-se a três pilares: os recursos são escassos; as pessoas maximizam, de modo racional, sua própria satisfação; o direito deve ser analisado sob o viés de três noções de eficiência, a saber: Eficiência Produtiva de Pareto, Eficiência dos Autores Kaldor e Hicks e a Eficiência Econômico Social.

O termo Eficiência pode ser entendido a partir de autores diversos: faz-se referência, aqui, às obras de Vilfredo Pareto, Kaldor-Hicks, Richard Posner e Everton das Neves Gonçalves. Em termos gerais, segundo Frank H. Stephen, Eficiência é fazer o "melhor com a menor quantidade de recursos disponíveis, reduzindo o desperdício e os custos, e buscando beneficiar os indivíduos" (STEPHEN, 1993, p. 40).

A Eficiência, para o autor Vilfredo Pareto - também conhecida como critério de Pareto -, significa que os bens devem ser transferidos de quem os valoriza pouco, em favor daqueles indivíduos que mais os valorizam, pois "uma distribuição dos recursos é eficiente se não for possível distribuir recursos de forma que pelo menos uma pessoa tenha situação melhorada e nenhuma outra pessoa tenha sua situação piorada" (STEPHEN, 1993, p. 41). Deste modo, haveria Eficiência, de acordo com Pareto, quando uma transação melhorasse a situação de uma pessoa, sem que a de outra pessoa fosse piorada.

A Eficiência para os autores Kaldor e Hicks significa que uma situação só será eficiente quando os ganhadores dessa situação puderem compensar os perdedores. Segundo Rachel Sztajn (2005, p. 76), o modelo de Eficiência em Kaldor Hicks significa que as leis escritas devem ser utilizadas para causar o máximo de bem-estar, em relação ao maior número de indivíduos, na medida em que os ganhos gerais compensem as possíveis perdas sofridas individualmente por alguns.

Tem-se a eficiência de Kaldor-Hicks, portanto, quando o produto de A excede os prejuízos de $\mathrm{B}$, aumentando, portanto, o excedente total, pois

\footnotetext{
haverá um ganho real no bem-estar da sociedade quando a redistribuição da riqueza importe que os agentes econômicos não desejem retornar à posição original, embora ainda recebessem, em dinheiro, o valor correspondente ao acréscimo em seus bens e serviços. (PIMENTA 2008, p. 101)
}

Já o Princípio da Eficiência Econômico Social - PEES, segundo Everton das Neves Gonçalves e Joana Stelzer (2014), significa a harmonização da ação econômica dos agentes, com critérios como a distributividade e justiça social, que são internalizados e equacionados, segundo cálculo de custo e benefício, quando da tomada de decisões no âmbito das relações humanas. 
O Princípio da Eficiência Econômico Social, conjugado com o Mínimo Ético Legal, inclui, na letra fria da lei ou no silogismo decisório, uma posição social inclusiva para que ocorra a realização dos direitos individuais e coletivos para além da forma abstrata da norma.

Portanto, a Análise Econômica do Direito visa proporcionar subsídios teóricos para que o Direito alcance o maior bem-estar, mediante a melhor alocação possível de bens, de modo que a Eficiência, em todos os seus níveis, desponta como o Principio básico-Elementar, o qual deve ser aplicado nas decisões judiciais e na elaboração da norma, notadamente, considerando os elementos do mínimo ético legal e da Eficiência Econômico-Social, conforme tópico a seguir.

\title{
4. O PRINCÍPIO DA EFICIÊNCIA ECONÔMICO SOCIAL - PEES
}

A Análise Econômica do Direito é uma teoria que propõe apresentar mais um método de intepretação e aplicação ao Direito para seus casos fáticos e jurídicos, mediante um dos elementos denominado Eficiência - que consiste na alocação dos recursos visando o menor custo sob o maior benefício.

Objetiva-se, assim, auxiliar os Juristas a efetuar decisões mediante critérios interdisciplinares com a Ciência Econômica, uma vez que nem sempre são consideradas as externalidades negativas e positivas pelos operadores do Direito no seu cálculo decisório ou legislativo. No entanto, não se pode atuar juridicamente fora dos limites Estatais ou efetuando um desequilíbrio social, razão pela qual desponta a necessidade de observar-se o Princípio da Eficiência Econômico-Social - PEES, que impõe o mínimo ético legal na obrigação de compensação. Os Autores Everton das Neves Gonçalves e Joana Stelzer (2014) detalham o Princípio:

\begin{abstract}
Trata-se da elaboração e aplicação da norma de forma economicamente eficiente, maximizando-se resultados esperados quando da adjudicação de direitos ou da determinação de obrigações, conforme caráter recíproco das ações e interesses, porém, considerando o reflexo social e o custo externo imposto à sociedade presente; ou mesmo, futura, de forma a serem compensados, na totalidade, os prejuízos impostos pelo ganho presente das partes envolvidas. Ainda, tem-se que o PEES considera, no cálculo econométrico, as variáveis de cunho social e temporal que, corretamente valoradas, devem ser internalizadas de forma que a relação de custo e benefício demonstre a realidade das utilidades auferidas quando se sacrificando determinados bens e serviços de outrem; considerado o maior número ou a totalidade dos agentes envolvidos.
\end{abstract}

Reflexo social e custo externo imposto à sociedade são categorias inerentes à Eficiência Econômico-Social, devendo a decisão "ótima” perquirir o interesse recíproco entre as partes e a 
compensação dos danos aos terceiros, isto é, calcular a distribuição e imposição de custos aos envolvidos.

A partir disso, desloca-se a noção tradicional de Justiça outrora defendida pelo Direito, como critério distributivo (tratar os iguais com igualdade e os desiguais com desigualdade) ou alteridade (tratar os outros do mesmo modo como gostaria de receber tratamento), para justiça econômico-jurídica, que se refere à compensação dos interesses sociais reciprocamente considerados.

Nesse sentido, a utilização do Princípio da Eficiência Econômico-Social e o do mínimo ético legal harmoniza-se com responsabilidade do Direito em assegurar o bem-estar social, ao internalizar nas decisões ou legislações os custos sociais das ações de seus agentes, presentes e futuros. Dessa forma, com o mencionado princípio, passa-se a trabalhar com o critério social e de inclusão do outro, mediante "funções não mercadológicas, variáveis que devem ser internadas no cálculo econômico segundo visão progressista" (GONÇALVES; STELZER, 2014).

Com isso, abandona-se a visão individualista e racional, voltada para o uso, por exemplo, punitivo e persecutório do Direito, para o critério eficiente dos recursos e das consequências sociais (externalidades), compensando-se os danos sofridos em nível social e de gerações futuras. Assim, aplicar a Eficiência no sistema jurídico, em especial, na seara criminal, pressupõe interpretar economicamente e construir a política criminal eficiente, a partir da tríade direito material, processo e execução penal.

O Princípio da Eficiência Econômico Social - PEES, quando aplicado juridicamente, demonstra que, embora o Congresso Nacional selecione determinadas condutas e as classifique como crimes, ainda sim, ter-se-á alta taxa de criminalidade, na medida em que nem todos os casos "selecionados" são efetivamente levados ao conhecimento das autoridades.

Assim, a Eficiência Econômico Social coloca em "xeque" que fatores econômicos contribuem para as taxas de criminalidade, mas o reflexo social e o custo externo imposto à sociedade, também devem ser considerados pelos juristas, consoante passa-se a explicar no tópico a seguir.

\section{ANÁliSE ECONÔMICA DO DIREITO PENAL: NOVA PERSPECTIVA DE APRECIAÇÃO DO FENÔMENO CRIMINAL}


Após se ter discorrido acerca da Análise Econômica do Direito e, em particular, do Princípio da Eficiência Econômico-Social, passa-se à exposição acerca da Análise Econômica do Crime, a fim de, posteriormente, cotejá-la com aquele preceito jurídico antes referido.

Assim como a Análise Econômica do Direito representa uma nova forma de encarar os fatos sociais - por uma lente não mais exclusivamente jurídica, mas também econômica -, a Análise Econômica do Crime (ou do Direito Penal - utilizar-se-ão indistintamente tais terminologias) proporciona uma nova compreensão do fenômeno criminal, sobretudo a partir do aporte de preceitos microeconômicos.

Muito embora as relações entre Direito e Economia tenham se travado, inauguralmente, em âmbito macroeconômico, e apesar de, da mesma forma, a Análise Econômica do Direito ter se debruçado, de início, sobre outros ramos do conhecimento jurídico (como o contratual), considera-se que tal teoria é plenamente aplicável ao Direito Penal.

De fato, a partir da obra de Coase,

outros autores, como Guido Calabresi, Gary Becker, William Landes e Richard Posner, passaram a tratar de temas variados sob a ótica da Economia, generalizando-se a introdução da disciplina nos cursos jurídicos tanto da Europa (Direito e Economia) como dos Estados Unidos (Análise Econômica do Direito) (SILVA, 2010, p. 468).

A Análise Econômica do Crime foi inauguralmente explorada por Gary Becker, em seu ensaio "Crime and punishment: an economic approach", no qual o autor associou a prática de crimes a preceitos microeconômicos. O economista americano, em seu escrito, parte do pressuposto de que há uma escolha racional, efetuada pelos indivíduos, entre o setor legal e o setor ilegal da economia (AMARAL; SHIKIDA, 2012, p. 303).

A premissa inicial de Becker consiste na acepção de que os agentes criminosos, em suas condutas, estão imbuídos de uma profunda racionalidade, a qual, em última instância, se baseia na ponderação de custos e benefícios (VIAPIANA, 2006, p. 37).

De fato, Becker busca demonstrar que os indivíduos, ao agirem racionalmente e perpetrarem um ilícito penal, equacionam os custos e benefícios decorrentes da atividade ilegal. Assume-se, assim, de acordo com a Análise Econômica do Crime, que um sujeito cometerá um delito se a utilidade esperada exceder a utilidade que se poderia obter mediante o dispêndio de tempo e outros recursos em outras atividades. A incursão de um sujeito na atividade criminosa, assim, não decorre de divergências entre as suas motivações e as dos demais, mas do fato de que os custos e benefícios de suas atividades - delitivas ou não - diferem. O autor sintetiza na seguinte afirmação a teoria por si desenvolvida: "aquele que decide sempre deseja aumentar o 
que foi conseguido para um plano mais elevado, denominado benefício marginal, que, por sua vez, leva ao incremento do obstáculo (denominado custo marginal)” (BECKER, 1984, p. 20).

Quanto à obra de Becker - que, vale dizer, não se restringiu à Análise Econômica do Crime -, Sousa ressalta justamente a sua amplitude e vastidão:

Diferentemente da obra de Coase, a de Becker é extremamente diversificada, mas é também das mais fecundas da teoria económica contemporânea. Segundo a Academia sueca, Becker 'alargou a análise económica a novos domínios dos comportamentos humanos e das relações humanas'. A sua atenção incidiu em campos tão importantes como a economia da pobreza e da discriminação social, a economia da educação, a análise económica do crime e da justiça criminal, a análise económica do direito da família, e ultimamente a análise económica do direito das drogas.

Becker também foi um inovador na análise económica do crime e da justiça criminal, ao procurar (1968) um critério de escolha de normas penais de que possa resultar um rendimento máximo da justiça criminal e um custo mínimo dos prejuízos sociais decorrentes da infracções e das atividades repressivas (SOUSA, 1992, p. 117).

Para novamente versar acerca da Análise Econômica do Direito Penal, após adendo atinente à obra de Gary Becker, ressalta-se que a acepção do economista americano coincide significativamente com aquela defendida séculos antes por Bentham - já apontado neste escrito como um dos responsáveis por fazer germinar, ainda que em um longínquo passado, a Análise Econômica do Direito -, o qual,

partindo da suposição de serem as pessoas racionais, concluiu que o controle penal se resume a estabelecer um conjunto de preços pelo delito, manipulando as variáveis que determinam o custo do castigo para o criminoso em potencial: a severidade do castigo e a probabilidade da pena.

Diante de tal raciocínio, mais afeiçoado ao campo da criminologia, a decisão de cometer ou não um delito ou vender um quadro seria sempre racional. Portanto, o controle penal estaria restrito a estabelecer um conjunto de preços ou custos pelo delito. A severidade do castigo e a probabilidade de benefícios pelo crime entrariam como variáveis a serem consideradas pelo criminoso (SILVA, 2010, p. 470) ${ }^{7}$.

Verifica-se, portanto, que muito embora a Análise Econômica do Direito tenha de fato florescido apenas na década de 1960, abordagens econômicas do crime já eram concebidas há longa data.

\footnotetext{
${ }^{7}$ Vale apontar que "a principal diferença entre a teoria desenvolvida por Becker e aquele encampada por Bentham, relegada pela moderna criminologia, é o fato de que este último considerava possível erradicar completamente, ao passo que o estudioso norte-americano concebia possível somente que se a reduzisse até um patamar mínimo" (CARDOSO, 2016, p. 63), uma vez que, a partir desse ponto, os custos para a redução do crime seriam maiores que os custos decorrentes das próprias práticas delitivas. Posição semelhante à de Becker, embora sob outro viés, é defendida por Magalhães Noronha, quando se refere ao crime e ao seu devenir histórico: "ele [o crime] surge com o homem e o acompanha através dos tempos, isso porque o crime, qual sombra sinistra, nunca dele se afastou" (NORONHA, 1991, p. 20).
} 
Bentham, porém, não foi o único pensador moderno a proceder a uma análise econômica dos crimes $^{8}$. Também Cesare Beccaria, pai do moderno Direito Penal, prestou valorosas contribuições àquela teoria que, séculos mais tarde, se denominaria Análise Econômica do Crime. É interessante e simbólico observar, tal como narra Sousa, que Beccaria, além de grande jurista, foi professor de economia politica, de forma que é, até certo ponto, natural que tenha sido ele um dos responsáveis pela germinação da teoria econômica do crime:

Beccaria, que aos 26 anos deslumbrou a Europa das Luzes com a sua crítica dos delitos e das penas (1764), tornou-se professor de economia política em Milão: as suas lições, publicadas postumamente em 1804, antecipavam muitas das ideias de Smith e Malthus. Adam Smith, o pai da economia política (1776), era sobretudo filósofo social, mas também jurista. Bentham, além de um dos maiores filósofos e juristas de sua época, foi também um grande economista, e lançou a ideia de que o cálculo prazer/sofrimento pode ser aplicado a todos os comportamentos humanos: foi aí que baseou a sua teoria utilitarista das penas e recompensas (1811) (SOUSA, 1992, p. 118).

É interessante observar, assim, que a mais remota origem da Análise Econômica do Direito Penal coincide, não à toa, com o próprio surgimento do Direito Penal como disciplina autônoma e dotada de um mínimo racionalismo - o que ocorre, sobretudo, a partir da edição, em 1764, da obra "Dos delitos e das penas", de Cesare Beccaria.

Em outras palavras, ainda que isso não floresça com tanta obviedade em alguns momentos da história do Direito Penal, pode-se dizer que o estudo dessa disciplina jamais esteve completamente dissociado dos fundamentos que hoje - e a partir de Becker - embasam a sua Análise Econômica. É dizer: já em seu próprio nascedouro o Direito Penal estava embebido em alguns dos preceitos que fundamentam a atual Análise Econômica do Crime.

A partir da concepção tanto de Becker quanto dos modernos Beccaria e Bentham de que o crime, tal como qualquer outra, é uma atividade profundamente racional -, a Análise Econômica do Direito Penal vale-se de teorias comportamentais que intentam explanar o processo de raciocínio que conduz à prática de um delito. Cuida-se, nomeadamente, da teoria da escolha racional, da teoria dos jogos e da teoria da dissuasão: cada qual intenta explicar, à sua maneira - embora as três sejam conciliáveis -, o cálculo racional dos agentes criminosos ${ }^{9}$.

\footnotetext{
${ }^{8}$ Evidentemente, a referência a uma análise econômica dos crimes não se insere na Escola da Law and Economics. Ainda assim, e mesmo que de forma de rudimentar, trata-se, sim, de uma análise econômica dos crimes, na medida em que se promove a interação de preceitos jurídicos e econômicos.

${ }^{9}$ Em virtude da limitação temática inerente a este trabalho, remete-se o leitor ao seguinte artigo: CARDOSO, Luiz Eduardo Dias. A efetividade da repressão aos crimes tributários à luz da Análise Econômica do Direito. In: XIX Semana Jurídica, 2015, Florianópolis. Anais XIX Semana Jurídica UFSC. Florianópolis: Centro Acadêmico XI de Fevereiro - CAXIF, 2016. p. 53-74. Outro aspecto relevante da Análise Econômica do Crime, mas que também escapa ao escopo deste escrito, é a existência de uma função matemática - na qual se incluem variáveis atinentes à
} 
Em seu ensaio, Becker ainda indaga o que define a quantidade e a espécie dos recursos e sanções de que o Estado se vale para colocar em prática a legislação penal, assim como reflete acerca da razão pela qual existem diferenças tão acentuadas na forma como cada lei é executada. Considerados esses questionamentos, bem como influxos econômicos e jurídicos, o autor avalia a quantidade de recursos e a extensão da punição necessárias à eficiência das diversas leis penais. A partir disso, também pretende aferir quantas e quais ofensas devem ser punidas e quantos infratores devem ficar impunes. Dessa forma, o autor conclui que a eficiência da legislação criminal vincula-se ao custo de detecção das atividades criminosas e de condenação dos infratores, bem como da resposta dos criminosos ao avanço da lei e da natureza das sanções (BECKER, 1974).

Vale ressaltar, ainda, que já na década de 60 - quando escreveu seu célebre ensaio -, Becker defendia que, apesar de negligenciado pelos economistas, o crime é uma atividade economicamente relevante; explana o autor que essa negligência decorria de uma concepção segundo a qual seria demasiadamente imoral a atividade ilegal para que fosse sistemática e cientificamente estudada (BECKER, 1974, p. 5). Essa assertiva, embora formulada por Becker há quase meio século, é plenamente aplicável ao Brasil, país em que o estudo do crime sob uma óptica econômica ainda é muito incipiente.

Diante das considerações atinentes à Análise Econômica do Crime já introduzidas, verifica-se que a interação de preceitos econômicos e jurídicos no processo de compreensão do fenômeno criminal consiste em tentativa "de racionalizar as políticas públicas existentes, tornar mais eficientes as normas penais, determinar quais as condutas que deveriam ser punidas e a correta forma de punição, além de maximizar os resultados quistos pela sociedade eminentemente, a segurança" (CARDOSO, 2016, p. 60).

Assim, uma vez introduzida a Análise Econômica do Direito - e, com maiores minúcias, o Princípio da Eficiência Econômico-Social -, bem como, mais especificamente, a Análise Econômica do Crime, cotejar-se-ão essas considerações precedentes, a fim de avaliar o impacto da inserção da eficiência como elemento integrante do Direito Penal, bem como a possibilidade de limitar a busca por tal valor mediante a utilização daquele preceito antes referido.

sanção, à detecção da prática criminosa e ao lucro decorrente desta última - que permite a aferição do custobenefício do cometimento de um crime. Uma vez mais, indica-se a consulta daquele artigo antes referido. 


\section{A bUSCA PELA EFICIÊNCIA do DIREITO PENAL E A SUA LIMITAÇÃo PELO PRINCÍPIO DA EFICIÊNCIA ECONÔMICO-SOCIAL}

Como se discorreu nos tópicos iniciais deste escrito, a Análise Econômica do Direito propugna, dentre várias outras medidas, a inserção da eficiência como vetor interpretativo. Cuida-se da acepção de que uma decisão, conquanto eficiente, pode não ser justa, mas toda decisão ineficiente será injusta.

A eficiência, evidentemente, não é apenas um vetor hermenêutico. Pelo contrário, também se deve tê-la em vista no momento da elaboração das normas, a fim de que o Direito cumpra o fim a que destina: a obtenção da paz social mediante o regramento de condutas.

A eficiência de que se vale a Análise Econômica do Direito, quando originariamente concebida por Posner, possuía um cerne monetário bastante destacado. Não à toa, o jurista norteamericano foi alvo de severas críticas - a mais contundente e célebre talvez seja a de Ronald Dworkin, que questiona: “a riqueza é um valor?” (DWORKIN, 2001, p. 351) $)^{10}$.

Com o passar do tempo e o refinamento daquela teórica jurídico-econômica, a eficiência sofreu reformulações.

Um dos mais ilustrativos exemplos é aquele antes mencionado, atinente ao Princípio da Eficiência Econômico-Social, cunhado pelo Professor Doutor Everton das Neves Gonçalves.

Retoma-se, assim, o problema inicialmente lançado, consistente em avaliar se pode a Análise Econômica do Crime valer-se daquele preceito com o fim de balizar a busca pela eficiência.

É relevante nesse sentido a contribuição de Wedy:

Percebe-se também a relevância da eficiência nos textos constitucionais e processuais, como os casos da Constituição brasileira e do Código de Processo Penal português (exposição de motivos). E aqui há de se reparar numa condição antropológicoexistencial para a emergência da eficiência.

$\mathrm{E}$, assim, não se trata mais de conceber a eficiência como um critério de otimização da riqueza ou do sistema, mas, sim, de entendê-la dentro de um contexto, dentro de uma unidade de sentido. Uma unidade de sentido entre o fundamento, a função e a finalidade do direito penal. $\mathrm{O}$ fundamento da relação onto-antropológica de cuidado de perigo, a função de proteção subsidiária e fragmentária dos bens jurídicos mais relevantes e a finalidade de realização da justiça e da paz jurídica. E, assim, transforma-se a eficiência. Agora, como um critério de otimização da legitimidade em direito penal, não mais conduzido por um princípio de promoção da riqueza, mas, sim, de otimização da justiça e de limitação da criminalização e da punibilidade.

\footnotetext{
${ }^{10}$ As críticas dirigidas à utilização da eficiência pela Análise Econômica do Direito são analisadas por Bruno Meyerhof Salama (2010) em texto sugestivamente intitulado "A História do declínio e queda do eficientismo na obra de Richard Posner".
} 
É o pensamento onto-antropológico do cuidado de perigo que permite trabalhar, legítima e democraticamente, a noção de eficiência para a seara penal, pois ele reduz o espectro penal, permitindo o dizer o sim e o dizer o não para a eficiência em direito penal. O não, para uma eficiência utilitarista e economicista, própria da razão calculadora. E o sim, para aquela finalidade eficiente que busca a justiça e a paz, por intermédio da conservação e do refazimento daquela relação fundamental ontoantropológica de cuidado de perigo. E o sim, também se impõe apontar, para aquela ideia de eficiência que limita a criminalização e a punibilidade em direito penal (2014).

Ou seja, trata-se da concepção de que a eficiência, muito embora seja, de fato, relevante, deve sofrer necessárias limitações.

Ditas limitações, na linha daquilo que se expôs em relação ao Princípio da Eficiência Econômico-Social, consistem nos direitos e garantias fundamentais assegurados aos cidadãos.

Como princípios penais elementares podem ser citados, apenas a título exemplificativo, a fragmentariedade, a subsidiariedade, o non bis in idem, o do Direito Penal como ultima ratio sobretudo como vetores que devem balizar a atuação do legislador na criação e na reforma de tipos penais. Esses preceitos são, de fato, óbices intransponíveis, para além dos quais não se pode estender a abrangência do Direito Penal.

De fato, uma vez observados esses limites impostos à eficiência, a Análise Econômica do Direito revela-se como valioso instrumento de interpretação das normas jurídicas - tanto daquelas já existentes quanto daquelas que ainda devem ser legisladas. Pode-se dizer, assim, que os influxos econômicos aportados pela AED são relevantes sobretudo em matéria de política criminal, à qual incumbe, nos dizeres de Dias, "definir os limites últimos do punível" (DIAS, 1983, p. 11).

Embora não seja inviável vislumbrar a utilidade da AED na aplicação dogmática do Direito Penal - a incidência do princípio da insignificância, por exemplo, parte de uma análise eminentemente (mas não exclusivamente) econômica -, é possível afirmar que aquele instrumental teórico tem grande valia quando em simbiose com a política criminal.

Do que se expôs até este ponto se extrai a criação de um espectro entre cujos limites o operador jurídico - seja o legislador, seja o juiz - pode transitar na busca pela solução mais eficiente, sem que isso implique violação a direitos e garantias fundamentais. Criam-se, efetivamente, fronteiras para o Direito Penal e, portanto, um território dentro do qual se pode buscar a solução mais eficiente.

A extrapolação desses limites, contudo, ainda que sob o pretexto de encontrar a solução mais eficiente, é proscrita pelo Princípio da Eficiência Econômico-Social, bem como pelo direito ou pela garantia eventualmente violados. Produz-se, assim, um fenômeno denominado por Alejandro Aponte de "eficientismo penal": 
El eficientismo penal, basado en una forma particular de la eficiência, se asienta sobre la visión de los derechos y garantías concebidos como obstáculos para el logro de la 'eficiencia' real del sistema penal. Se trata de modelos de respuesta punitiva, ligados a un uso instrumental y perverso de la figura de la detención preventiva, tal como se acaba de resenãr. Se trata de modelos que restringen, severamente, y a nombre de la eficiência, los derechos fundamentales y las garantias judiciales a todo nível, que conciben el control judicial como control meramente formal y no material, que privilegiam los medios sobre los fines, en temas tan delicados como las intervenciones corporales, la captura, los allanamientos: la eficiência o supuesta eficiência, prevalece como telos, y los medios deben adecuarse a esse fin absoluto (APONTE, 2006, p. 141142).

Assim, embora crescente o seu estudo, a Análise Econômica do Direito não está imune a críticas, nomeadamente aquelas relativas ao risco de que o caráter interdisciplinar daquela teoria produza um fenômeno indesejável, que é o de converter toda a teoria econômica no único conhecimento relevante para o estudo do Direito, olvidando preceitos básicos de garantia de direitos fundamentais. Trata-se, em linhas gerais, do sentido das críticas dirigidas à obra de Posner, sobretudo no que toca à utilização da eficiência (em uma faceta quase que exclusivamente monetária) como vetor interpretativo do Direito.

É, portanto, exatamente nesse contexto, que o respeito aos direitos fundamentais particularmente às garantias de caráter penal-material e processual penal - apresenta-se como adequado instrumento de contenção daquela receada conversão: de um caráter interdisciplinar, obtido da conjugação de preceitos jurídicos e econômicos, para uma natureza estritamente econômica.

Dessa forma, conquanto sejam significativas as críticas à Análise Econômica do Direito, sobretudo em sua inicial e mais conhecida vertente - proposta por Posner e a Escola de Chicago -, é possível aplicar tal leitura do fenômeno jurídico sem renunciar às especificidades do método jurídico, isto é, sem subordinar a aplicação do Direito à obtenção de resultados economicamente positivos, o que, em última instância, corresponderia ao condicionamento da aplicação das normas jurídicas a um referencial alheio ao Direito.

A utilização do Princípio da Eficiência Econômico-Social como preceito balizador da Análise Econômica do Direito - particularmente, aqui, no que toca ao Direito Penal - decorre, ainda, da necessidade de harmonizar aquela teoria às instituições peculiares do sistema jurídico da Civil Law.

De fato, uma vez que aquela teoria se originou e foi primariamente desenvolvida em solo no qual vige a Common Law, não se pode proceder à sua simples transposição para a Civil Law sem que se promovam as necessárias adaptações. 
No âmbito das Ciências Penais, essa adaptação é ainda mais imprescindível, dada a relevância dos bens jurídicos em jogo - a liberdade, de um lado, e o bem eventualmente tutelado pela prática delitiva, de outro.

Exatamente nesse sentido, Alexandre Morais da Rosa formula pontual crítica quanto à importação de institutos jurídicos ínsitos à Common Law sem que se proceda à sua necessária adaptação às instituições pátrias:

Ainda que não dito, muitas das reformas recentes no ordenamento se deram pela fusão equivocada e irrefletida de tradições jurídicas, trazendo-se, não raro, institutos estranhos ao Direito Continental. Esse comércio de institutos do direito anglo-saxão, todavia, não acontece sem o estabelecimento de uma tensão decorrente da diferença de tradições filosóficas, isto é, de uma matriz causa-efeito; parte-se, sem muita aproximação, para um panorama pragmático, no qual a eficiência prepondera. Nessa perspectiva de diálogo entre tradições diversas é que surgem possíveis justificações teóricas para, dentre outras reformas (BARROS, 2008; GIACOMOLLI 2008), a (i) sumarização e aceleração (VIRILIO, 1999) de procedimentos; (ii) mitigação da obrigatoriedade da ação penal; (iii) possibilidade de negociação monetária (conciliação) e inclusão equivocada da vítima no processo penal (BARROS, 2008); (iv) suspensão condicional do processo; (v) aplicação de discursos consequencialistas no campo do direito e do processo penal; (vi) discussão sobre os custos do processo e da pena; (vii) restrição recursal (Lei n. 9.099/95); e (viii) delação premiada (ROSA, 2011, 246-247).

As reformas citadas pelo jurista são, inegavelmente, relevantes, na medida em que subverteram alguns dos mais elementares preceitos sobre os quais se escora a ciência penal à brasileira.

Precisamente quanto à necessidade de adaptação das novidades legislativas ao sistema jurídico pátrio, Alexandre Morais da Rosa ainda leciona:

\begin{abstract}
Nesse contexto há uma manifesta tensão entre o Direito Continental e o Direito AngloSaxão. Os institutos próprios de cada um dos Sistemas acabam sendo intercambiados sem a devida aproximação democrática, isto é, as novidades legislativas são implementadas em tradições filosóficas distintas, daí a perplexidade de muitas das alterações legislativas recentes (v. g. Delação Premiada). Não se trata de reconhecer que a tradição Continental é melhor ou pior, dado que essa discussão é inoperante. O que importa é que as tradições implicam práticas e modos de pensar diferenciados. (ROSA, 2011, p. 241).
\end{abstract}

Essa ressalva relativa à adaptação da Análise Econômica do Direito e de seus preceitos para as realidades jurídicas nas quais for implantada tem singular relevância em terras brasileiras, uma vez que se cuida de país periférico e em desenvolvimento. Demanda-se, assim, uma aplicação da Análise Econômica do Direito que se adéque à realidade jurídica e social em que se insere, e não pode se equivaler à prática levada a cabo nas nações desenvolvidas nos 
países desenvolvidos, porquanto a salvaguarda de alguns direitos possui relevância maior do que nos territórios desenvolvidos, que já consolidaram um modelo de sistemas jurídico e social (POSNER, 2010, p. XVIII).

Reputa-se verificada, assim, a hipótese segundo a qual o Princípio da Eficiência Econômico-Social é relevante instrumento de que deve o operador jurídico valer-se na aplicação da Análise Econômica do Direito - e, particularmente, em sua faceta criminal -, seja a fim de promover a adequada adaptação daquela teoria jurídico-econômica à realidade brasileira, seja com o objetivo de promover a contenção e a limitação da busca pela eficiência como objeto a ser perseguido nas decisões judiciais e na elaboração das leis.

\section{CONSIDERAÇÕES FINAIS}

O presente artigo visou a responder à indagação atinente à aplicabilidade do Princípio da Eficiência Econômico-Social à Análise Econômica do Crime.

Para tanto, principiou com uma exposição relativa à Análise Econômica do Direito, a fim de demonstrar que tal teoria, gestada na Common Law norte-americana, intenta promover a simbiose entre Direito e Economia para que se efetue uma compreensão interdisciplinar dos complexos fenômenos sociais que são apresentados ao operador jurídico. Discorreu-se, neste particular, acerca da utilização da eficiência como vetor interpretativo e como valor a ser juridicamente perseguido.

$\mathrm{Na}$ sequência, apresentou-se o Princípio da Eficiência Econômico-Social, que figura como preceito limitador dessa perseguição da eficiência, a fim de que tal se opere dentro dos limites representados pelos direitos e garantias assegurados pelo Estado a seus cidadãos.

Adiante, a abordagem voltou-se à Análise Econômica do Crime - uma das variadas vertentes da teoria jurídico-econômica aqui explorada -, com especial ênfase à obra de Gary Becker, na medida em que foi ele o precursor de estudos em tal área. Elaboraram-se referências, ainda, a Cesare Beccaria e Jeremy Bentham, pensadores modernos responsáveis por lançar as mais incipientes bases daquilo que, dois séculos mais tarde, viria a ser a Análise Econômica do Crime.

Avançou-se, então, à etapa final deste artigo, em que se promoveu o cotejo entre os elementos até então abordados: o Princípio da Eficiência Econômico-Social e a Análise Econômica do Crime. Intentou-se demonstrar que a adoção daquele preceito é indispensável para 
que se possa promover a aplicação da teoria jurídico-econômica em questão, na medida em que se trata de instrumento teórico gestado em sistema jurídico - a Common Law - distinto do brasileiro - a Civil Law - e porque, no manejo daquele instrumental teórico, é indispensável que se salvaguardem os direitos e garantias constitucionalmente assegurados aos cidadãos ou, em outras palavras, porque a busca pela eficiência não pode desbordar dos limites impostos à Análise Econômica do Direito por aqueles mesmos direitos e garantias fundamentais.

Reputou-se verificada, assim, a hipótese inicialmente conjecturada em resposta ao problema acerca do qual orbitou este trabalho. Em outras palavras, considerou-se evidenciada a utilidade do Princípio da Eficiência Econômico-Social como balizador da busca pela eficiência promovida pela Análise Econômica do Direito - e, em particular para este artigo, pela Análise Econômica do Crime.

\section{REFERÊNCIAS}

ANDERSON, Perry. Balanço do neoliberalismo. In: SADER, Emir; GENTILLI, Pablo. (Orgs.). Pós-neoliberalismo: as políticas sociais e o Estado democrático. 6. ed. Rio de Janeiro: Paz e Terra, 2003.

APONTE, Alejandro. Guerra y derecho penal de enemigo. Reflexión crítica sobre el eficientismo penal de enemigo. Bogotá: Ibañez, 2006.

BECCARIA, Cesare. Dos delitos e das penas. 3. ed. São Paulo. CL EDIJUR, 2014.

BECKER, Gary S.. Crime and punishment: an economic approach. In: BECKER, Gary S.; LANDES, William M.. Essays in the economic of crime and punishment. 1974.

CARDOSO, Luiz Eduardo Dias A efetividade da repressão aos crimes tributários à luz da Análise Econômica do Direito In: XIX Semana Jurídica, 2015, Florianópolis.

Anais XIX Semana Jurídica UFSC. Florianópolis: Centro Acadêmico XI de Fevereiro - CAXIF, 2016. p. 53-74.

COASE, Ronald. The problem of social cost. Journal of Law and Economics, n. 3, p. 1-23, 1960.

DIAS, Jorge de Figueiredo. Os novos rumos da política criminal e o direito penal português do futuro. Revista da Ordem dos Advogados. Lisboa: Ordem dos Advogados, 1983.

DWORKIN, Ronald. Uma questão de princípio. São Paulo: Martins Fontes, 2001.

GONÇALVES, Everton das Neves. A teoria de Posner e a sua aplicabilidade na ordem constitucional econômica brasileira de 1988. (Dissertação). Mestrado em Direito. Florianópolis 
- UFSC, 1997.

GONÇALVES, E. N.; STELZER, J.. Eficiência e direito: pecado ou virtude; uma incursão pela análise econômica do direito. Revista Jurídica (FIC), v. 28, p. 77-122, 2012.

. Princípio da Eficiência Econômico-Social no Direito Brasileiro: a tomada de decisão normativo-judicial. In: Revista Sequência. UFSC, Florianópolis, SC, Brasil, v. 35, n. 68 (2014) https://periodicos.ufsc.br/index.php/sequencia/article/view/21777055.2013v35n68p261>. Acesso em: 17 set. 2016.

GONÇALVES, E. N.; STELZER, J.; SOUZA, G. L.. Princípio da Eficiência Econômico-Social (PEES): possibilidade epistêmica para o Direito segundo a Ciência Econômica. In: Anais do I Encontro Brasileiro de Epistemologia Jurídica: limites e possibilidades do conhecimento científico no Direito, 2014, Florianópolis, SC. Anais do I Encontro Brasileiro de Epistemologia Jurídica: limites e possibilidades do conhecimento científico no Direito. Florianópolis, SC: José Boiteux. v. 1.

MERCADO, Pacheco Pedro. El analisis economico del derecho uma reconstrucion teorica. Madri: Centro de Estúdios Constitucionales, 1994.

NORONHA, Magalhães E. Direito Penal. vol. 1. São Paulo: Saraiva, 1991.

PACHECO, Pedro Mercado. El Analisis Economico del Derecho - una reconstruccion teorica. Madri: Centro de Estudios Constitucionales, 1994.

PIMENTA, Eduardo Goulart; BOGLIONE, Stefano. O princípio da preservação da empresa em crise econômico-financeira em Direito \& Economia. Revista Faculdade Mineira de Direito (PUCMG), vol. 11, p. 101, 2008.

POSNER, Richard. A economia da justiça. Traduzido por Evandro Ferreira e Silva. São Paulo: WMF Martins Fontes, 2010.

. Economic Analysis of Law. 7. ed. New York: Aspen Publishers, 2007.

. Para além do direito. Traduzido por Evandro Ferreira da Silva. São Paulo: WMF Martins Fontes, 2009.

. Problemas de Filosofia do Direito. São Paulo: Martins Fontes, 2007.

ROEMER, Andrés. Introducción al análisis económico del derecho. Tradução de José Luis Pérez Hernández, 1994.

ROSA, Alexandre Morais da. Direito e processo penal juntos? (Des)caminhos do ensino jurídico. In: RODRIGUES; Horácio Wanderlei; ARRUDA JÚNIOR, Edmundo Lima de. (Org.). Educação jurídica: temas contemporâneos. 1. ed. Florianópolis: Fundação Boiteux, 2011, v. 1, p. 259-282.

ROSSETTI, José Paschoal. Introdução à Economia. 14 ed. rev., atual., ampl. São Paulo: Atlas, 
1990.

SALAMA, Bruno Meyerhof. In: Latin American and Caribbean Law and Economics Association. Janeiro, 2008.

SALAMA, Bruno Meyerhof. A História do declínio e queda do eficientismo na obra de Richard Posner. In: LIMA, Maria Lúcia L. M. Pádua (Coord.). Trinta Anos de Brasil: diálogos entre Direito e Economia. São Paulo: Saraiva, 2010.

SHIKIDA, Pery Francisco Assis; AMARAL, Thiago Bottino do. Análise Econômica do Crime. In: TIMM, Luciano Benetti (Org.). Direito e economia no Brasil. São Paulo: Editora Atlas S.A., 2012, p. 296-317.

SILVA, Fernando Quadros da. A magnitude da lesão nos crimes contra o Sistema Financeiro Nacional: uma abordagem à luz da análise econômica do Direito. In: BALTAZAR Jr., José Paulo; HIROSE, Tadaaqui. Curso Modular de Direito Penal. v. 2. Florianópolis: Conceito, 2010.

SOUSA, João Ramos de. Gary Becker: também na fronteira da economia e do direito. Sub Judice: Justiça e sociedade, Coimbra, n. 3, p.117-120, mai./ago. 1992.

STEPHEN, Frank H. Teoria econômica do direito. Tradução Neusa Vitale. São Paulo: Makron Books, 1993.

SZTAJN, Rachel. Law \& Economics. IN Stajn, Rachel; Zylberstajn, Décio (Org.). Direito e Economia: Análise Econômica do Direito e das Organizações. Rio de Janeiro: Elseivier, 2005.

SZTAJN, Rachel; ZYLBERSZTAJN, Décio. (org.). Direito e Economia. São Paulo: Campus, 2013.

VIAPIANA, Luiz Tadeu. Economia do Crime: uma explicação para a formação do criminoso. Porto Alegre: AGE, 2006.

WEDY, M. Tedesco. Eficiência e direito penal, in Contribuciones a las Ciencias Sociales. abr. 2014. Disponível em: www.eumed.net/rev/cccss/28/dereito-penal.html. Acesso em 10. set. 2016. 